\title{
Blow-up phenomena for the sixth-order boussinesq equation with fourth-order dispersion term
}

\author{
Huan Zhang ${ }^{1}$ and Jun Zhou ${ }^{1}$ \\ ${ }^{1}$ Southwest University
}

June 19, 2020

\begin{abstract}
This paper deals with the sixth-order boussinesq equation with fourth-order dispersion term. By suitable assumptions on the initial values, the conditions on finite time blow-up of solutions are given. Moreover, the upper and lower bounds of the blow-up time are also investigated
\end{abstract}

\section{Hosted file}

upper-lower-bounds-for-b-p-time-7.pdf available at https://authorea.com/users/335191/ articles/461047-blow-up-phenomena-for-the-sixth-order-boussinesq-equation-with-fourthorder-dispersion-term 